\title{
Definicije naziva povezanih s pojedinačnim makromolekulama, makromolekulskim nakupinama, polimernim otopinama i amorfnim polimernim tvarima (I. dio) ${ }^{* * *}$
}

Prispjelo 30. studenoga 2015.

Prihvaćeno 18. svibnja 2016.

\section{Preporuke IUPAC 2014. \\ Preporuke HDKI i HKD 2016.}

Pripravila radna skupina u sastavu:

Robert Stepto*, Taihyun Chang, Pavel Kratochvíl, Michael Hess,

Kazuyuki Horie, Takahiro Sato i Jiři Vohlídal

Preveo:

Marko Rogošić *

Sveučilište u Zagrebu, Fakultet kemijskog inženjerstva i tehnologije

\begin{abstract}
\| Sažetak
Ovaj dokument definira nazive povezane sa svojstvima pojedinačnih makromolekula, makromolekulskih nakupina, polimernih otopina i amorfnih polimernih tvari. U odjeljku o polimernim otopinama i amorfnim polimernim tvarima razmatraju se opće i termodinamičko nazivlje, razrijeđene otopine, fazno ponašanje, transportna svojstva, metode raspršenja svjetlosti i separacijske metode. Preporuke su revizija i proširenje nazivlja IUPAC-a objavljenog 1989., koje se ticalo pojedinačnih makromolekula, makromolekulskih nakupina i razrijeđenih polimernih otopina. Uvedeni su novi nazivi koji pokrivaju glavna teorijska i eksperimentalna saznanja do kojih se u međuvremenu došlo. Polielektroliti nisu uključeni.

\| Ključne riječi

Amorfni polimeri, polimerne mase, IUPAC-ov Odjel za polimere, makromolekulske nakupine, makromolekule, fazno ponašanje polimera, polimerne otopine, termodinamika polimera, svojstva raspršenja svjetlosti, separacijske metode, transportna svojstva
\end{abstract}

\section{Sadržaj}

Uvodne napomene 145

1. Pojedinačne makromolekule 146

2. Makromolekulske nakupine 151

Literatura 155

Summary 156

*Prof. dr. sc. Marko Rogošić, mrogosic@fkit.hr

** Autor za korespondenciju: Robert Stepto, School of Materials, The University of Manchester, Manchester M1 7HS, UK, e-mail: rftstepto@gmail.com.

*** Izvornik: Robert Stepto, Taihyun Chang, Pavel Kratochvíl, Michael Hess, Kazuyuki Horie, Takahiro Sato, Jiř̌ Vohlídal, Definitions of terms relating to individual macromolecules, macromolecular assemblies, polymer solutions, and amorphous bulk polymers (IUPAC Recommendations 2014), Pure Appl. Chem. 87(1) (2015) 71-120.

Recenzenti: Davor Kovačević, Branko Kunst, Ivan Šmit, Valerije Vrček

\section{Uvodne napomene}

Ovaj je dokument dio niza što ga objavljuje Odbor za nazivlje polimera odnosno ranije Povjerenstvo za nomenklaturu makromolekula, koje se bavi definicijama naziva u polimernoj znanosti. ${ }^{1}$

Ovdje prikazane preporuke revizija su i proširenje nazivlja koje se tiče pojedinačnih makromolekula, makromolekulskih nakupina i razrijeđenih polimernih otopina. ${ }^{2}$ Posebice, nazivima koji se tiču polimernih otopina dodani su i oni povezani s polurazrijeđenim i koncentriranim polimernim otopinama i amorfnim polimernim tvarima. Sada su pokrivena područja pojedinačnih makromolekula, makromolekulskih nakupina, polimernih otopina i amorfnih polimernih tvari, opći i termodinamički nazivi, razrijeđene otopine, fazno ponašanje, transportna svojstva, svojstva raspršenja svjetlosti i separacijske metode. Za nazive povezane s drugim aspektima makromolekula i polimernih materijala čitatelj se upućuje na Compendium of Polymer 
Terminology and Nomenclature. ${ }^{1}$ Prikazane definicije ne obuhvaćaju polielektrolite.

Napomena prevoditelja: U definicijama IUPAC-ovih preporuka kosim tiskom navedeni su nazivi koji su u istom dokumentu zasebno obrađeni. U ovom dokumentu neki nazivi navedeni kosim tiskom nisu zasebno obrađeni i takvi su označeni zvjezdicom (*), a u poglavlju 5. Popis naziva dodana im je engleska istovrijednica s naznakom obrađenog naziva u čijoj definiciji se pojavljuju. U slučaju istoznačnica, svakoj je dodana oznaka normativnog statusa (preporučeni nazivp ${ }^{p}$ dopušteni naziv ${ }^{\mathrm{d}}$, nepreporučeni naziv $^{n}$. Na kraju ovih preporuka, a radi lakšeg snalaženja, navedena su dva abecedna kazala naziva i to hrvatsko-englesko (5. Popis naziva, tablica 1) i englesko-hrvatsko (5. Popis naziva, tablica 2).

\section{Pojedinačne makromolekule}

\section{1. relativna molekulska masa, $M_{r}$} (relative molecular mass)

molekulska težina $^{\mathrm{n}}$ (molecular weight)

Omjer mase molekule i unificirane atomske jedinice mase. $^{3}$

Napomena 1: Unificirana atomska jedinica mase je jedna dvanaestina mase atoma izotopa ugljika 12 u njegovu osnovnom jezgrenom i elektronskom stanju. ${ }^{3}$

Napomena 2: Relativna molekulska masa ili molekulska težina $^{\mathrm{n}}$ je neimenovani broj i ne smiju mu se pridruživati nikakve jedinice.

Napomena 3: Naziv "molekulska" može se rabiti i za česticu koja se sastoji od više od jedne molekule, poput kompleksa, agregata, micele itd.

Napomena 4: Vidi molarna masa i relativna molarna masa.

\section{2. stupanj polimerizacije (DP), $X$ (degree of polymerization)}

Broj monomernih jedinica u makromolekuli, oligomernoj molekuli, bloku ili lancu.

\section{3. lanac (u polimernoj znanosti) (chain)}

Cijela makromolekula ili njezin dio, oligomerna molekula ili blok koji se sastoji od ravnog ili razgranatog slijeda konstitutivnih jedinica između dviju graničnih konstitutivnih jedinica, od kojih svaka može biti ili krajnja skupina ili točka grananja ili bilo kojim drugim karakterističnim svojstvom obilježena jedinica makromolekule. ${ }^{4}$

Napomena 1: Osim u ravnim jednonitnim makromolekulama, definicija lanca može biti donekle proizvoljna.

Definicije koje slijede u ovom odjeljku, a uključuju "lance", razvijene su na osnovi jednonitnih lanaca. Međutim ponekad se mogu primijeniti i na druge vrste lanaca, poput ljestvastih ili spiro-lanaca.

Napomena 2: Prstenasta makromolekula nema krajnjih grupa, ali se unatoč tome može smatrati lancem

Napomena 3: Između odabranih rubnih točaka može postojati bilo koji cijeli broj točaka grananja.

\section{4. odsječak lanca ${ }^{\mathrm{p}}$, segment lanca ${ }^{\mathrm{d}}$ (chain segment) odsječak ${ }^{p}$, segment ${ }^{d}$ (segment)}

Skupina međusobno povezanih atoma kostura lanca, uključujući i njihove bočne skupine, ako ih ima, takva da se sam lanac može prikazati kao lanac segmenata.

\section{5. unutarmolekulska međudjelovanja kratkog dosega (short-range intramolecular interaction)}

Sterička ili druga međudjelovanja koja uključuju atome, skupine, ili oboje, međusobno udaljene svega nekoliko kosturnih veza duž lanca.

Napomena 1: Međudjelujuće atome ili skupine uobičajeno dijeli manje od deset slijednih kosturnih veza u lancu.

Napomena 2: Ako se unutarmolekulska međudjelovanja mogu sasvim jasno razlučiti od međumolekulskih, može se ispustiti riječ "unutarmolekulska".

\section{6. unutarmolekulska međudjelovanja dugog dosega (long-range intramolecular interaction)}

Međudjelovanja odsječaka znatno udaljenih u slijedu uzduž lanca koji se tijekom molekulskog uvijanja povremeno približavaju jedan drugome.

Napomena 1: Ova je vrsta međudjelovanja blisko povezana s isključenim volumenom segmenta koji inače odražava neto međudjelovanja, što uključuju segmente svih molekula u otopini i molekule otapala.

Napomena 2: Ako se unutarmolekulska međudjelovanja mogu sasvim jasno razlučiti od međumolekulskih, može se ispustiti riječ "unutarmolekulska".

\section{7. konformer (conformer)}

Jedan iz skupa stereoizomera od kojih svaki karakterizira konformacija koja odgovara izraženom minimumu energije. $^{3}$

\section{8. rotamer (rotamer)} rotacijski izomer (rotational isomer)

Jedan iz skupa konformera koji potječe od ograničene rotacije oko jednostruke veze ${ }^{3}$.

1.9. rotacijsko izomerno stanje (u polimernoj znanosti) (rotational isomeric state)

konformacijsko stanje veze (u polimernoj znanosti) (bond-conformational state)

Rotamer definiran relativnim kutom zakreta oko kosturne veze jednonitnog lanca.

Napomena 1: Rotacijsko se izomerno stanje dogovorom definira za slijed tri uzastopne kosturne veze kao torzijski (diedarski) kut $(\phi)$ između ravnina što ih određuju prve dvije odnosno druge dvije veze. Primjerice, za lanac sastavljen samo od jednostrukih $\mathrm{C}-\mathrm{C}$ kosturnih veza, $\phi \approx 0^{\circ}$ 
određuje (planarno) rotacijsko izomerno stanje trans $(t)$, a $\phi \approx \pm 120^{\circ}$ određuje rotacijsko izomerno stanje gauche $(g \pm)$.

Napomena 2: Postoji i alternativno označavanje. Primjerice, $\phi= \pm 120^{\circ}$ odnosno $\pm 60^{\circ}$ mogu se primijeniti da označe stanja $t$ i g士, kojima se mogu pridružiti i simboli T, G+, i G-, prema lit. ${ }^{5}$. Stanja trans i gauche ili konformeri također su poznati kao antiperiplanarni konformeri* i sinklinalni konformeri*3,6§

Oznake kao u napomeni 1 uveli su Flory i suradnici ${ }^{5}$ i danas se najčešće primjenjuju u polimernoj znanosti.

Napomena 3: Energije rotacijskih izomernih stanja određene su unutarmolekulskim međudjelovanjima kratkog dosega.

\$Napomena prevoditelja: U hrvatskoj se terminologiji upotrebljavaju i izrazi "antizvjezdasti" odnosno "zvjezdasti" konformeri.

\subsection{0. konformacija lanca (chain conformation)}

Konformaciju lanca definira slijed njegovih konformacijskih stanja veza.

Napomena: Ako ne postoji mogućnost zabune, može se ispustiti riječ "lanca".

\subsection{1. neometane dimenzije (unperturbed dimensions)}

Dimenzije makromolekule hipotetski određene samo unutarmolekulskim međudjelovanjima kratkog dosega ili određene unutarmolekulskim međudjelovanjima kratkog i dugog dosega u theta-stanju polimerne otopine ili u amorfnoj polimernoj tvari.

Napomena: Za linearne fleksibilne makromolekule dimenzije se uobičajeno izražavaju kao odgovarajući prosjeci (momenti) raspodjela udaljenosti krajeva lanca i polumjera vrtnje, a za nelinearne fleksibilne makromolekule obično se primjenjuju jedino momenti raspodjele polumjera vrtnje.

\subsection{2. neometano konformacijsko stanje}

(unperturbed conformational state)

Konformacija lanca koja odgovara neometanim dimenzijama.

\subsection{3. ometane dimenzije (perturbed dimensions)}

Dimenzije makromolekule u polimernoj otopini koja nije u theta-stanju.

Napomena: Vidi napomenu u definiciji 1.11. za tumačenja značenja "dimenzija".

1.14. polumjer vrtnje, $s$, jedinica: $n m$ ili SI jedinica: $m$ (radius of gyration)

Za makromolekulu koja se sastoji od $n$ masenih elemenata, masa $m_{i}, i=1,2 \ldots n$, smještenih na stalnim udaljenostima $s_{i}$ od centra mase, polumjer vrtnje je kvadratni korijen masenog prosjeka vrijednosti $s_{i}{ }^{2}$ svih masenih elemenata, tj.:

$$
S=\left(\sum_{i=1}^{n} m_{i} s_{i}^{2} / \sum_{i=1}^{n} m_{i}\right)^{1 / 2}
$$

Napomena: Kao maseni elementi obično se odabiru mase kosturnih skupina koje sačinjavaju makromolekulu, primjerice $-\mathrm{CH}_{2}-\mathrm{u}$ poli(metilenu).

1.15. neometani polumjer vrtnje, $s_{0}$ jedinica: $\mathrm{nm}$ ili SI jedinica: $m$ (unperturbed radius of gyration)

Polumjer vrtnje makromolekule u neometanom konformacijskom stanju.

\subsection{6. korijen srednjeg kvadrata polumjera vrtnje, $\left\langle s^{2}\right\rangle^{1 / 2}, R_{\mathrm{g}}$, jedinica: $\mathrm{nm}$ ili SI jedinica: $\mathrm{m}$ (root-mean-square radius of gyration)}

Za fleksibilnu molekulu koja se sastoji od $n$ masenih elemenata, masa $m_{i}, i=1,2 \ldots n$, smještenih na statističko-mehaničkim srednjim kvadratima udaljenosti $\left\langle s_{i}{ }^{2}\right\rangle$ od središta mase, korijen srednjeg kvadrata polumjera vrtnje je kvadratni korijen masenog prosjeka vrijednosti $\left\langle s_{i}{ }^{2}\right\rangle$ svih masenih elemenata, tj.:

$$
\left\langle s^{2}\right\rangle^{1 / 2}=\left(\sum_{i=1}^{n} m_{i}\left\langle s_{i}{ }^{2}\right\rangle / \sum_{i=1}^{n} m_{i}\right)^{1 / 2}
$$

Napomena 1: Kao maseni elementi obično se odabiru mase kosturnih skupina koje sačinjavaju makromolekulu, primjerice $-\mathrm{CH}_{2}-\mathrm{u}$ poli(metilenu).

Napomena 2: $\left\langle s_{i}{ }^{2}\right\rangle$ je statističko-mehanički prosjek $s_{i}{ }^{2}$ po svim konformacijama lanca.

Napomena 3: Polumjer vrtnje je parametar koji karakterizira veličinu makromolekule kao vremenski uprosječenog sfernog područja u laboratorijskim koordinatama.

1.17. srednji kvadrat polumjera vrtnje, $\left\langle s^{2}\right\rangle$, jedinica $\mathrm{nm}^{2}$ ili SI jedinica: $\mathrm{m}^{2}$ (mean-square radius of gyration)

Za fleksibilnu makromolekulu koja se sastoji od $n$ masenih elemenata, masa $m_{i}, i=1,2 \ldots n$, smještenih na statističko-mehaničkim srednjim kvadratima udaljenosti $\left\langle s_{i}{ }^{2}\right\rangle$ od središta mase, srednji kvadrat polumjera vrtnje je maseni prosjek vrijednosti $\left\langle s_{i}{ }^{2}\right\rangle$ svih masenih elemenata, tj.:

$$
\left\langle s^{2}\right\rangle=\left(\sum_{i=1}^{n} m_{i}\left\langle s_{i}{ }^{2}\right\rangle / \sum_{i=1}^{n} m_{i}\right) .
$$

1.18. korijen srednjeg kvadrata neometanog polumjera vrtnje, $\left\langle s_{0}{ }^{2}\right\rangle^{1 / 2}$, jedinica: $\mathrm{nm}$ ili SI jedinica: $\mathrm{m}$ (root-mean-square unperturbed radius of gyration)

Korijen srednjeg kvadrata polumjera vrtnje makromolekule koja ima neometane dimenzije. 
Napomena: Ne preporučuje se tradicionalno primjenjivana oznaka $\left\langle s^{2}\right\rangle_{0}^{1 / 2}$ jer ona označuje neometani prosjek korijena \langle\rangle$_{0}^{1 / 2}$, kvadrata polumjera, $s^{2}$ a ne korijen srednjeg, \langle\rangle$^{1 / 2}$, kvadrata neometanog polumjera, $s_{0}^{2}$.

\subsection{9. srednji kvadrat neometanog polumjera vrtnje, \\ $\left\langle\mathrm{s}_{0}{ }^{2}\right\rangle$, jedinica: $\mathrm{nm}^{2}$ ili $\mathrm{SI}$ jedinica: $\mathrm{m}^{2}$ (mean-square unperturbed radius of gyration)}

Srednji kvadrat polumjera vrtnje makromolekule koja ima neometane dimenzije.

1.20. vektor krajeva, $r$, jedinica $\mathrm{nm}$ : ili SI jedinica: $\mathrm{m}$ (end-to-end vector)

Vektor koji spaja dva kraja linearnog lanca određene konformacije.

1.21. neometani vektor krajeva, $r_{\mathrm{o}}$ jedinica $\mathrm{nm}$ : ili $\mathrm{SI}$ jedinica: $m$ (unperturbed end-to-end vector)

Vektor koji spaja dva kraja linearnog lanca određene konformacije, pri čemu lanac ima neometane dimenzije.

1.22. udaljenost krajeva, $r$, jedinica $\mathrm{nm}$ : ili SI jedinica: $m$ (end-to-end distance)

Duljina vektora krajeva.

1.23. neometana udaljenost krajeva, $r_{0}$, jedinica $n m$ : ili SI jedinica: $m$ (unperturbed end-to-end distance)

Duljina neometanog vektora krajeva.

\subsection{4. korijen srednjeg kvadrata udaljenosti krajeva, $\left\langle r^{2}\right\rangle^{1 / 2}$, jedinica: $\mathrm{nm}$ ili SI jedinica: $m$ (root-mean-square end-to-end distance)}

Kvadratni korijen statističko-mehaničkog srednjeg kvadrata udaljenosti krajeva linearnog lanca, uprosječenog po svim konformacijama lanca.

Napomena: Ako ne može doći do zabune, može se upotrijebiti naziv udaljenost krajeva*.

1.25. srednji kvadrat udaljenosti krajeva, $\left\langle r^{2}\right\rangle$, jedinica: $\mathrm{nm}^{2}$ ili SI jedinica: $\mathrm{m}^{2}$ (mean-square end-to-end distance)

Statističko-mehanički srednji kvadrat udaljenosti krajeva linearnog lanca, uprosječen po svim konformacijama lanca.

\subsection{6. korijen srednjeg kvadrata neometane udaljenosti krajeva, $\left\langle r_{\mathrm{o}}{ }^{2}\right\rangle^{1 / 2}$, jedinica: $\mathrm{nm}$ ili SI jedinica: $\mathrm{m}$ (root-mean-square unperturbed end-to-end distance)}

Korijen srednjeg kvadrata udaljenosti krajeva lanca koji ima neometane dimenzije.
Napomena: Ako ne može doći do zabune, može se upotrijebiti naziv neometana udaljenost krajeva*.

\subsection{7. srednji kvadrat neometane udaljenosti krajeva $\left\langle r_{\mathrm{o}}{ }^{2}\right\rangle$, jedinica: $\mathrm{nm}^{2}$ ili SI jedinica: $\mathrm{m}^{2}$ (mean-square unperturbed end-to-end distance)}

Srednji kvadrat udaljenosti krajeva lanca koji ima neometane dimenzije.

Napomena: $\left\langle r_{0}{ }^{2}\right\rangle$ hipotetskog, dovoljno dugačkog, linearnog lanca, identičnih jednostrukih kosturnih veza koje imaju međusobno neovisna rotacijska izomerna stanja dan je jednadžbom:

$$
\left\langle r_{\mathrm{o}}{ }^{2}\right\rangle=n l^{2} \frac{(1+\cos \theta)(1+\langle\cos \phi\rangle)}{(1-\cos \theta)(1-\langle\cos \phi\rangle)}
$$

gdje je $n$ broj kosturnih veza duljine / i komplementa valentnog kuta $\theta$, a $\langle\cos \phi\rangle$ je prosjek kosinusa torzijskih kutova $\phi$ definiranih sljedovima triju uzastopnih kosturnih veza. Jednadžba je korisna za razumijevanje značenja karakterističnog omjera, steričkog faktora i efektivne duljine veze.

\subsection{8. karakteristični omjer, $C_{n}\left(C_{\infty} \operatorname{kad} n \rightarrow \infty\right)$ (characteristic ratio)}

Omjer srednjeg kvadrata neometane udaljenosti krajeva linearnog lanca i produkta $n\left\langle\left.\right|^{2}\right\rangle$, gdje je $n$ broj kosturnih veza $\mathrm{u}$ lancu, a $\left\langle\left.\right|^{2}\right\rangle$ je srednji kvadrat duljine kosturne veze, tj.:

$$
C_{n}=\frac{\left\langle r_{0}^{2}\right\rangle}{n\left\langle l^{2}\right\rangle} .
$$

Napomena 1: $\left\langle I^{2}\right\rangle=\sum_{i=1}^{n} l_{i}^{2} / n$. Za lanac identičnih kosturnih veza duljine $I,\left\langle I^{2}\right\rangle=I^{2}$.

Napomena 2: Za hipotetski, dovoljno dugačak linearni lanac istovrsnih jednostrukih kosturnih veza s međusobno neovisnim rotacijskim izomernim stanjima, jednadžba (1) u definiciji 1.27. pokazuje da vrijednost $C_{n}$ ovisi o vrijednostima $\cos \theta \mathrm{i}\langle\cos \phi\rangle$. Općenito, i za stvarne lance vrijednost $C_{n}$ ovisi o vrijednostima valentnih kutova kosturnih veza i torzijskih konformacijskih kutova veza, iako može biti teško izvesti analitički izraz za $C_{n}$.

\subsection{9. slobodno rotirajući lanac (freely rotating chain)}

Hipotetski lanac bez unutarmolekulskih međudjelovanja kratkog odnosno dugog dosega, koji se sastoji od beskonačno tankih pravocrtnih kosturnih veza s torzijskim kutovima sljedova triju uzastopnih kosturnih veza koji mogu poprimiti svaku vrijednost s jednakom vjerojatnošću.

\subsection{0. korijen srednjeg kvadrata udaljenosti krajeva slobodno rotirajućeg lanca, $\left\langle r_{\mathrm{o}, \mathrm{f}}^{2}\right\rangle^{1 / 2}$, jedinica: $\mathrm{nm}$ ili SI jedinica: $m$ (root-mean-square end-to-end distance of a freely rotating chain)}

Korijen srednjeg kvadrata udaljenosti krajeva linearnog slobodno rotirajućeg lanca. 
Napomena: Ako ne može doći do zabune, može se upotrebljavati naziv "slobodno rotirajuća udaljenost krajeva" (freely rotating end-to-end distance).

\subsection{1. srednji kvadrat udaljenosti krajeva slobodno rotirajućeg lanca, $\left\langle r_{\mathrm{o}, \mathrm{f}}^{2}\right\rangle$, jedinica: $\mathrm{nm}^{2}$ ili $\mathrm{SI}$ jedinica: $\mathrm{m}^{2}$ (mean-square end-to-end distance of a freely rotating chain)}

Srednji kvadrat udaljenosti krajeva linearnog slobodno rotirajućeg lanca.

Napomena: $\left\langle r_{\mathrm{off}}^{2}\right\rangle$ hipotetskog, dovoljno dugačkog linearnog slobodno rotirajućeg lanca identičnih jednostrukih kosturnih veza dan je izrazom:

$$
\left\langle r_{\mathrm{o}, \mathrm{f}}^{2}\right\rangle=\left.n\right|^{2} \frac{1+\cos \theta}{1-\cos \theta}
$$

gdje je $n$ broj kosturnih veza duljine / i komplementa valentnog kuta $\theta$.

\subsection{2. sterički faktor, $\sigma$ (steric factor)}

Kvadratni korijen omjera srednjeg kvadrata neometane udaljenosti krajeva promatranog lanca i srednjeg kvadrata udaljenosti krajeva slobodno rotirajućeg lanca iste strukture, u graničnom slučaju beskonačne duljine lanca, tj.:

$$
\sigma=\left(\left\langle r_{\mathrm{o}}^{2}\right\rangle /\left\langle r_{\mathrm{o}, \mathrm{f}}^{2}\right\rangle\right)^{1 / 2}
$$

Napomena 1: Sterički je faktor vrsta karakterističnog omjera povezanog sa strukturom lanca, vidi karakteristični omjer.

Napomena 2: Vrijednost steričkog faktora odražava utjecaj steričkih smetnji na slobodnu rotaciju. Za hipotetski, dovoljno dugačak lanac identičnih jednostrukih kosturnih veza s međusobno neovisnim rotacijskim izomernim stanjima jednadžbe (1) i (2) u definicijama 1.27., odnosno 1.31. pokazuju da vrijednost $\sigma$ ovisi o $\langle\cos \phi\rangle$. Općenito, i za stvarne lance vrijednost $\sigma$ ovisi o vrijednostima torzijskih konformacijskih kutova veza iako može biti teško izvesti analitički izraz za $\sigma$.

Napomena 3: Vrijednost $\sigma$ može se primijeniti kao mjera krutosti linearnog lanca.

\subsection{3. efektivna duljina veze, $b$, jedinica: $\mathrm{nm}$ ili $\mathrm{SI}$} jedinica: m (effective bond length)

Kvadratni korijen omjera srednjeg kvadrata neometane udaljenosti krajeva linearnog lanca i broja kosturnih veza, tj.:

$$
b=\left(\left\langle r_{\mathrm{o}}{ }^{2}\right\rangle / n\right)^{1 / 2} .
$$

Napomena 1: Efektivna duljina veze vrsta je karakterističnog omjera povezanog sa strukturom lanca, vidi karakteristični omjer.

Napomena 2: $b^{2}$ je srednji kvadrat neometane udaljenosti krajeva po jednoj kosturnoj vezi. Za hipotetski, dovoljno dugačak lanac identičnih jednostrukih kosturnih veza s međusobno neovisnim rotacijskim izomernim stanjima jednadžba (1) u definiciji 1.27. pokazuje da vrijednost $b$ ovi- si o vrijednostima I, $\cos \theta \mathrm{i}\langle\cos \phi\rangle$. Općenito, i za stvarne lance vrijednost $b$ ovisi o vrijednostima duljina i valentnih kutova kosturnih veza te torzijskih konformacijskih kutova veza iako može biti teško izvesti analitički izraz za $b$.

\subsection{4. slobodno povezani lanac (freely jointed chain) nasumce lutajući lanac ${ }^{n}$ (random-walk chain) nasumce leteći lanac ${ }^{\mathrm{n}}$ (random-flight chain)}

Hipotetski linearni lanac koji se sastoji od beskonačno tankih pravocrtnih segmenata (poveznica) jednolike duljine, od kojih svaki može poprimiti svaku prostornu orijentaciju s jednakom vjerojatnošću, neovisnu od orijentacije svojih susjeda.

Napomena 1: U slobodno povezanom lancu dvije ili više poveznica mogu istodobno zauzimati isti volumen.

Napomena 2: Korijen srednjeg kvadrata udaljenosti krajeva slobodno povezanog lanca koji se sastoji od $m$ poveznica duljine I' dan je izrazom:

$$
\left\langle r_{\mathrm{o}}{ }^{2}\right\rangle^{1 / 2}=m^{1 / 2} l^{\prime}
$$

1.35. duljina konture, $r_{\max }$ jedinica: $n m$ ili $\mathrm{SI}$ jedinica: $m$ (contour length)

\section{duljina potpuno ispruženog lanca}

(fully extended chain length)

Maksimalna udaljenost krajeva promatranog lanca.

Napomena 1: Za lanac identičnih jednostrukih kosturnih veza, duljina konture jednaka je udaljenosti krajeva lanca u kojem sve veze zauzimaju planarno rotacijsko izomerno stanje trans ${ }^{\S}$. Za lanac složenije strukture može se odrediti samo približna vrijednost duljine konture.

Napomena 2: Duljina konture slobodno povezanog lanca koji se sastoji od $m$ poveznica duljine $I^{\prime}$ dan je izrazom:

$$
r_{\max }=m l^{\prime}
$$

Napomena 3: "Duljinom konture" naziva se ponekad i zbroj duljine svih kosturnih veza jednonitne polimerne molekule. Ne preporučuje se upotreba ovog naziva za tu svrhu.

§Napomena prevoditelja: Preciznije - antiperiplanarnu ili antizvjezdastu konformaciju.

\subsection{6. ekvivalentni slobodno povezani lanac (equivalent freely jointed chain)}

Hipotetski slobodno povezani lanac s istim srednjim kvadratom udaljenosti krajeva lanca i duljinom konture kao stvarni linearni lanac koji ima neometane dimenzije.

Napomena: Broj poveznica, $m$, i njihova duljina, $l^{\prime}$, određuju se iz srednjeg kvadrata udaljenosti krajeva lanca ${ }^{\S},\left\langle r_{0}{ }^{2}\right\rangle$ i duljine konture, $r_{\max }$ stvarnoga lanca primjenom jednadžbi (3) i (4) iz definicija 1.34 i 1.35, uz:

$$
m=\frac{r_{\max }{ }^{2}}{\left\langle r_{\mathrm{o}}{ }^{2}\right\rangle} \mathrm{i} I^{\prime}=\frac{\left\langle r_{\mathrm{o}}{ }^{2}\right\rangle}{r_{\max }} .
$$


Primjerice, za polimetilen pri sobnoj temperaturi, jedna slobodna poveznica odgovara otprilike broju od 10 stvarnih kosturnih veza $\mathrm{C}-\mathrm{C}$.

${ }^{\S}$ Napomena prevoditelja: Izvorni tekst spominje srednji kvadrat udaljenosti krajeva, a primjenjuje se simbol za srednji kvadrat neometane udaljenosti krajeva.

\subsection{Kuhnov odsječak ${ }^{p}$, Kuhnov segment ${ }^{d}$ \\ (Kuhn segment)}

statistički odsječak ${ }^{p}$, statistički segment ${ }^{\mathrm{d}}$

(statistical segment)

ekvivalentna slobodna poveznican

(equivalent freely jointed link)

Odsječak ili poveznica ekvivalentnog slobodno povezanog lanca

\subsection{8. duljina Kuhnova odsječka ${ }^{p}$, duljina Kuhnova} segmenta ${ }^{\mathrm{d}}, l^{\prime}, I_{\mathrm{K}}$, jedinica: $\mathrm{nm}$ ili $S \mathrm{SI}$ jedinica: $\mathrm{m}$ (Kuhn segment length)

duljina statističkog odsječka ${ }^{p}$, duljina statističkog segmenta $^{\mathrm{d}}$ (statistical segment length)

duljina ekvivalentne slobodne poveznice ${ }^{n}$ (freely jointed link length)

Duljina Kuhnova odsječka. ${ }^{\S}$

${ }^{\S}$ Napomena prevoditelja: I u engleskom se izvorniku naziv tumači samim sobom.

\subsection{9. neispresijecani slobodno povezani lanac (self-avoiding random-walk chain)}

Slobodno povezani lanac podvrgnut ograničenju da segmenti ne mogu presijecati jedan drugoga

Napomena 1: U modelu neispresijecanog lanca podrazumijeva se da segmenti imaju konačni volumen tako da dva ili više njih ne mogu zauzimati isti volumen istodobno.

Napomena 2: Model neispresijecanog slobodno povezanoga lanca primjenjuje se za prikaz polimernog lanca s isključenim volumenom.

${ }^{\S}$ Napomena prevoditelja: Predloženi hrvatski termin ne slijedi engleski izvornik; doslovni bi prijevod glasio: samoizbjegavajući nasumce lutajući lanac.

\subsection{0. makromolekulsko klupko (macromolecular coil)}

Prikaz makromolekule u kojem su segmenti raspodijeljeni oko neke točke u prostoru.

Napomena: Kao točka u prostoru obično se odabire središte mase molekule ili kraj lanca.

\subsection{1. statističko klupko (statistical coil)}

Makromolekulsko klupko koje zauzima fleksibilna makromolekula u otopini ili u amorfnomu čvrstom polimeru.

Napomena: Statističko klupko može upućivati na fleksibilnu molekulu ometanih dimenzija ili pak u theta-stanju.

\subsection{2. slučajno klupko (random coil) Gaussovo klupko (Gaussian coil)}

Statističko klupko koje zauzima linearna, jednonitna makromolekula u otopini u theta-stanju ili u amorfnoj polimernoj tvari.

Napomena: Gustoća vjerojatnosti vektora krajeva makromolekule koja tvori nasumično klupko slijedi Gaussovu raspodjelu.

\subsection{3. crvoliki lanac (worm-like chain) Kratky-Porodov lanac (Kratky-Porod chain)}

Hipotetski, beskonačno tanak linearni lanac neprekidne zakrivljenosti gdje je smjer zakrivljenosti u svakoj točki nasumičan.

Napomena: Model se može primijeniti za opis lanaca različitog stupnja fleksibilnosti, od slobodno povezanih lanaca do krutih štapova, i posebno je koristan za predstavljanje ukrućenih, jednonitnih i višenitnih lanaca.

1.44. perzistencijska duljina, a, jedinica: $\mathrm{nm}$ ili SI jedinica: $\mathrm{m}$ (persistence length)

Za linearni lanac, prosječna projekcija vektora krajeva na tangentu konture lanca u njegovoj krajnjoj točki, u graničnom slučaju beskonačne duljine lanca.

Napomena 1: Perzistencijska je duljina osnovno obilježje crvolikog lanca.

Napomena 2: Perzistencijska je duljina jednaka polovici duljine Kuhnova segmenta ekvivalentnog slobodno povezanog lanca $\left(a=l^{\prime} / 2\right)$.

\subsection{5. krutost lanca (chain stiffness)}

Parametar koji opisuje udaljenost krajeva linearnog, jednonitnog makromolekulskog lanca neometanih dimenzija u odnosu na udaljenost krajeva modelnog makromolekulskog lanca koji nije pod utjecajem unutarmolekulskih međudjelovanja kratkog dosega.

Napomena: Mjere krutosti lanca su i sterički faktor, $\sigma$, i duljina Kuhnova segmenta, l', i perzistencijska duljina, a.

\subsection{6. kratkolančana grana (short-chain branch)}

Oligomerni izdanak makromolekulskog lanca. ${ }^{1}$

\subsection{7. dugolančana grana (long-chain branch)}

Makromolekulski izdanak makromolekulskog lanca. ${ }^{1}$

1.48. $g$-faktor, $g$ (g-factor) faktor sažimanja polumjera vrtnje (radius of gyration contraction factor) faktor sažimanja (contraction factor) geometrijski faktor sažimanja (geometric contraction factor) 
Omjer srednjeg kvadrata polumjera vrtnje razgranate molekule, $\left\langle s_{\mathrm{b}}{ }^{2}\right\rangle, \mathrm{i}$ iste veličine u svakom drugom pogledu identične linearne molekule, $\left\langle s_{1}{ }^{2}\right\rangle$, jednake relativne molekulske mase, $\mathrm{u}$ istom otapalu te pri istoj temperaturi, tj. $g=\left\langle s_{\mathrm{b}}{ }^{2}\right\rangle /\left\langle s_{\mathrm{l}}{ }^{2}\right\rangle$

Napomena: g-faktor je veličina koja karakterizira utjecaj dugolančanih grana na dimenzije razgranate molekule. Usporedi s definicijom 1.49 .

\subsection{9. $g^{\prime}$-faktor, $g^{\prime}$ ( $g^{\prime}$-factor) viskoznosni faktor sažimanja (viscosity contraction factor) \\ hidrodinamički faktor sažimanja \\ (hydrodynamic contraction factor)}

Omjer intrinzične viskoznosti razgranate molekule, $\left[\eta_{\mathrm{b}}\right]$, i iste veličine u svakom drugom pogledu identične linearne molekule, $\left[\eta_{1}\right]$, jednake relativne molekulske mase, u istom otapalu te pri istoj temperaturi, tj. $g^{\prime}=\left[\eta_{\mathrm{b}}\right] /\left[\eta_{l}\right]$.

Napomena: $g^{\prime}$-faktor je veličina koja karakterizira utjecaj dugolančanih grana na dimenzije razgranate molekule. Usporedi s definicijom 1.48 .

\section{Nakupine makromolekula}

\section{1. heterogenost sastava}

(compositional heterogeneity)

Varijacije elementarnog sastava od molekule do molekule koje se uobičajeno susreću u kopolimerima.

\section{2. konstitucijska heterogenost (constitutional heterogeneity)}

Promjene konstitucije od molekule do molekule kod molekula koje su jednolike s obzirom na elementarni sastav.

Napomena: Primjer je polimer koji se sastoji od linearnih i razgranatih molekula; drugi je primjer statistički kopolimer koji obuhvaća dvije izomerne konstitucijske jedinice.

\section{3. jednoliki polimer ${ }^{p}$, uniformni polimer ${ }^{d}$ (uniform polymer) molekulski jednoliki polimer ${ }^{\mathrm{p}}$, molekulski uniformni polimer ${ }^{d}$ (molecularly uniform polymer)}

Polimer sastavljen od molekula jednolikih s obzirom na relativnu molekulsku masu i konstituciju.

Napomena 1: Polimer koji se sastoji od smjese linearnih i razgranatih lanaca jednolike relativne molekulske mase ne smatra se jednolikim.

Napomena 2: Kopolimer koji se sastoji od linearnih molekula jednolike relativne molekulske mase i jednolikog elementarnog sastava, ali različitog rasporeda sljedova različitih vrsta monomernih jedinica nije jednolik (npr. kopolimer koji sadrži molekule s nasumičnim rasporedom monomernih jedinica te molekule s rasporedom monomernih jedinica u blokovima).
Napomena 3: Polimer jednolik s obzirom na relativnu molekulsku masu ili pak konstituciju može se nazvati “jednolikim" uz primjenu pripadnog atributa (npr. "polimer jednolik s obzirom na relativnu molekulsku masu").

Napomena 4: Pridjevi monodisperzan* i polidisperzan* duboko su ukorijenjeni u literaturi unatoč svojstvenoj nedeskriptivnosti i unutarnjoj proturječnosti. Preporučuju se pridjevi jednolik* i nejednolik*. Vidi također disperznost, definicija 2.28.

\section{4. nejednoliki polimer ${ }^{\mathrm{p}}$, neuniformni polimer ${ }^{\mathrm{d}}$ (non-uniform polymer) \\ molekulski nejednoliki polimer ${ }^{p}$, molekulski neuniformni polimer ${ }^{\mathrm{d}}$ (molecularly non-uniform polymer)}

Polimer koji se sastoji od molekula nejednolikih s obzirom na relativnu molekulsku masu ili konstituciju, ili oboje.

Napomena: Vidi definiciju 2.3., napomene 1 - 4 .

2.5. molarna masa, $M$, jedinica: $\mathrm{g} \mathrm{mol}^{-1}$ ili $\mathrm{SI}$ jedinica: $\mathrm{kg} \mathrm{mol}^{-1}$ (molar mass)

Masa podijeljena množinom tvari.

Napomena 1: U ovom kontekstu, prema lit. 3, "množina tvari" je broj molekula podijeljen Avogadrovom konstantom, $N_{\mathrm{A}}\left[=6,02214179(30) \cdot 10^{23} \mathrm{~mol}^{-1}\right]$.

Napomena 2: Upotrebljava li se jedinica $\mathrm{g} \mathrm{mol}^{-1}$, numeričke vrijednosti molarne mase, relativne molekulske mase i relativne molarne mase jednake su.

Napomena 3: Naziv "molarni" može se također upotrebljavati za čestice koje se sastoje od više od jedne molekule, poput kompleksa, agregata, micela, itd.

\section{6. relativna molarna masa, $M_{\mathrm{r}}$ (relative molar mass)}

Molarna masa podijeljena s $1 \mathrm{~g} \mathrm{~mol}^{-1}$, prema lit. ${ }^{3}$.

Napomena 1: Veličina $1 \mathrm{~g} \mathrm{~mol}^{-1}$ ponekad se naziva standardnom molarnom masom.

Napomena 2: Relativna molarna masa i molekulska težinan imaju identične brojčane vrijednosti.

2.7. prosjek molarne mase, $M_{\mathrm{k}}$, jedinica: $\mathrm{g} \mathrm{mol}^{-1}$ ili SI jedinica: $\mathrm{kg} \mathrm{mol}^{-1}$ (molar-mass average)

prosjek molekulske težine ${ }^{n}, M_{r, k}$ (molecular-weight average)

prosjek relativne molarne mase, $M_{r, k}$ (relative-molar-mass average)

prosjek relativne molekulske mase, $M_{r, k}$ (relative-molecular-mass average)

Bilo koji prosjek molarne mase, molekulske težine ${ }^{n}$, relativne molarne mase ili relativne molekulske mase nejednolikoga polimera, gdje simbol k označava vrstu prosjeka.

Napomena 1: Različite oznake koje mogu stajati umjesto $k$ dane su u nazivima 2.8. -2 2.12. Primjerice, uz $k \equiv n$, definiraju se vrijednosti brojčanoga prosjeka. 
Napomena 2: U načelu, moguće je definirati beskonačan broj prosjeka molarne mase, ali svega se nekoliko vrsta prosjeka može izravno odrediti eksperimentom. Najvažniji se prosjeci definiraju preko jednostavnih momenata funkcija raspodjele i određuju se metodama primijenjenim na sustave u termodinamičkoj ravnoteži, poput osmometrije, statičkog raspršenja svjetlosti i sedimentacijske ravnoteže. Hidrodinamičke metode, u pravilu, daju kompleksnije prosjeke molarne mase.

Napomena 3: Bilo koji prosjek molarne mase može se definirati preko masenih udjela ili molarnih udjela. $U$ ovom se dokumentu najvažniji prosjeci molarne mase definiraju preko masenih udjela, $w_{M}$, čestica molarne mase $M$. Te su definicije u najbližoj vezi s eksperimentalnim određivanjima prosjeka molarne mase.

Napomena 4: Zadnja su tri naziva istoznačnice. Veličine su bezdimenzijske i ne pridružuju im se nikakve jedinice.

2.8. brojčani prosjek molarne mase, $M_{n}$, jedinica: $\mathrm{g} \mathrm{mol}^{-1}$ ili SI jedinica: $\mathrm{kg} \mathrm{mol}^{-1}$ (number-average molar-mass)

$$
M_{\mathrm{n}}=\frac{1}{\sum_{M}\left(w_{M} / M\right)}
$$

brojčani prosjek molekulske težine ${ }^{\mathrm{n}}, M_{\mathrm{r}, \mathrm{n}}$ (number-average molecular weight)

brojčani prosjek relativne molarne mase, $M_{r, n}$ (number-average relative molar mass)

brojčani prosjek relativne molekulske mase, $M_{r, n}$ (number-average relative molecular mass)

$$
M_{r, n}=\frac{1}{\sum_{M_{r}}\left(w_{M_{r}} / M_{r}\right)}
$$

Napomena 1: Za definicije oznaka vidi definiciju 2.7.

Napomena 2: Zadnja su tri naziva istoznačnice. Veličine su bezdimenzijske i ne pridružuju im se nikakve jedinice.

2.9. maseni prosjek molarne mase, $M_{\mathrm{m}}, M_{\mathrm{w}}$ jedinica: $\mathrm{g} \mathrm{mol}^{-1}$ ili SI jedinica: $\mathrm{kg} \mathrm{mol}^{-1}$ (mass-average molar-mass)

$$
M_{\mathrm{m}}=M_{\mathrm{w}}=\sum_{M} w_{M} M
$$

maseni prosjek molekulske težine ${ }^{\mathrm{n}}, M_{\mathrm{r}, \mathrm{m}}, M_{\mathrm{r}, \mathrm{w}}$ (mass-average molecular weight)

maseni prosjek relativne molarne mase, $M_{r, m}$ (mass-average relative molar mass)

maseni prosjek relativne molekulske mase, $M_{r, m}$ (mass-average relative molecular mass)

$$
M_{r, m}=M_{r, w}=\sum_{M_{r}} w_{M_{r}} M_{r}
$$

Napomena 1: Za definicije oznaka vidi definiciju 2.7.

Napomena 2: Zadnja su tri naziva istoznačnice. Veličine su bezdimenzijske i ne pridružuju im se nikakve jedinice.
2.10. z-prosjek molarne mase, $M_{\mathrm{z}}$ jedinica: $\mathrm{g} \mathrm{mol}^{-1}$ ili SI jedinica: $\mathrm{kg} \mathrm{mol}^{-1}$ (z-average molar-mass)

$$
M_{z}=\frac{\sum_{M} w_{M} M^{2}}{\sum_{M} w_{M} M}
$$

z-prosjek molekulske težine ${ }^{n}, M_{r, z}$ (z-average molecular weight)

z-prosjek relativne molarne mase, $M_{r, z}$ (z-average relative molar mass)

z-prosjek relativne molekulske mase, $M_{r, z}$ (z-average relative molecular mass)

$$
M_{r, z}=\frac{\sum_{M_{r}} w_{M_{r}} M_{r}^{2}}{\sum_{M_{r}} w_{M_{r}} M_{r}}
$$

Napomena 1: Za definicije oznaka vidi definiciju 2.7.

Napomena 2: Zadnja su tri naziva istoznačnice. Veličine su bezdimenzijske i ne pridružuju im se nikakve jedinice.

2.11. $(z+1)$-prosjek molarne mase, $M_{z+1}$, jedinica: $\mathrm{g} \mathrm{mol}^{-1}$ ili SI jedinica: $\mathrm{kg} \mathrm{mol}^{-1}$ $((z+1)$-average molar-mass $)$

$$
M_{\mathrm{z}+1}=\frac{\sum_{M} w_{M} M^{3}}{\sum_{M} w_{M} M^{2}}
$$

$(z+1)$-prosjek molekulske težine ${ }^{\mathrm{n}}, M_{\mathrm{r}, \mathrm{z}+1}$ $((z+1)$-average molecular weight $)$

$(z+1)$-prosjek relativne molarne mase, $M_{r, z+1}$ $((z+1)$-average relative molar mass $)$

$(z+1)$-prosjek relativne molekulske mase, $M_{r, z+1}$ $((z+1)$-average relative molecular mass $)$

$$
M_{r, z+1}=\frac{\sum_{M_{r}} W_{M_{r}} M_{r}^{3}}{\sum_{M_{r}} W_{M_{r}} M_{r}^{2}}
$$

Napomena 1: Za definicije oznaka vidi definiciju 2.7.

Napomena 2: Zadnja su tri naziva istoznačnice. Veličine su bezdimenzijske i ne pridružuju im se nikakve jedinice.

2.12. viskoznosni prosjek molarne mase, $M_{v}$ jedinica: $\mathrm{g} \mathrm{mol}^{-1}$ ili SI jedinica: $\mathrm{kg} \mathrm{mol}^{-1}$ (viscosity-average molar-mass)

$$
M_{v}=\left[\sum_{M} w_{M} M^{a}\right]^{1 / a}
$$

viskoznosni prosjek molekulske težine ${ }^{\mathrm{n}}, M_{\mathrm{r}, \mathrm{v}}$ (viscosity-average molecular weight)

viskoznosni prosjek relativne molarne mase, $M_{r, v}$ (viscosity-average relative molar mass)

viskoznosni prosjek relativne molekulske mase, $M_{r, v}$ (viscosity-average relative molecular mass) 


$$
M_{r, v}=\left[\sum_{M_{r}} W_{M_{r}} M_{r}^{a}\right]^{1 / a}
$$

gdje je a eksponent Mark-Houwinkove jednadžbe, $[\eta]=K M^{a}$.

Napomena 1: Za definicije oznaka vidi definiciju 2.7.

Napomena 2: Zadnja su tri naziva istoznačnice. Veličine su bezdimenzijske i ne pridružuju im se nikakve jedinice.

Napomena 3: Eksponent a treba razlikovati od ugodivog parametra nekih od funkcija raspodjele i od perzistencijske duljine.

2.13. prividna molarna masa, $M_{\text {app }}$ jedinica: $\mathrm{g} \mathrm{mol}^{-1}$ ili SI jedinica: $\mathrm{kg} \mathrm{mol}^{-1}$ (apparent molar mass)

prividna molekulska težina ${ }^{n}, M_{r, a p p}$

(apparent molecular-weight)

prividna relativna molarna masa, $M_{r, a p p}$

(apparent relative-molar-mass)

prividna relativna molekulska masa, $M_{r, a p p}$

(apparent relative-molecular-mass)

Molarna masa, molekulska težinan ${ }^{n}$, relativna molarna masa ili relativna molekulska masa izračunata iz eksperimentalnih podataka bez primjene prikladnih korekcija.

Napomena 1: Zadnja su tri naziva istoznačnice. Veličine su bezdimenzijske i ne pridružuju im se nikakve jedinice.

Napomena 2: Primjeri korekcija su one za konačnu koncentraciju polimera, asocijaciju (polimernih molekula), preferiranu sorpciju, heterogenost sastava, konstitucijsku heterogenost te također za eksperimentalne podatke dobivene instrumentom (često kromatografijom isključenja po veličini, SEC) baždarenim standardnim uzorcima poznatih molarnih masa polimera konstitucijski različitog od onoga koji je analiziran.

\subsection{4. korekcija zbog polimolekularnosti (polymolecularity correction)}

Korekcija koja se primjenjuje na ovisnost nekog svojstva o molarnoj masi ili relativnoj molekulskoj masi, eksperimentalno određena za polimer nejednolik s obzirom na relativnu molekulsku masu, da bi se dobila odgovarajuća ovisnost za polimer jednolik s obzirom na relativnu molekulsku masu.

\subsection{5. prosječni stupanj polimerizacije, $X_{k}$ (average degree of polymerisation)}

Bilo koji prosjek stupnja polimerizacije polimera, gdje $k$ označava vrstu prosjeka.

Napomena: Za homopolimer definicije 2.7 - 2.12 primjenjive su izravno na prosjeke stupnja polimerizacije kada se u formulama $M_{\mathrm{r}}$ zamijeni s $X$.

2.16. funkcija raspodjele (u polimernoj znanosti) (distribution function)

raspodjela (u polimernoj znanosti) (distribution)
Normalizirana funkcija koja daje udio polimera specifične vrijednosti ili specifičnog područja vrijednosti, slučajne varijable (ili slučajnih varijabli).

Napomena 1: Funkcija raspodjele može biti diskretna, tj. može poprimati neke određene vrijednosti slučajne varijable (ili vrijednosti slučajnih varijabli), ili pak kontinuirana, tj. može poprimati bilo koju vrijednost slučajne varijable (ili vrijednosti slučajnih varijabli) u zadanom području. Većina raspodjela u polimernoj znanosti je svojstveno diskretna, ali ih je često prikladno smatrati kontinuiranima ili primjenjivati funkcije raspodjele koje su svojstveno kontinuirane.

Napomena 2: Funkcija raspodjele može biti integralna funkcija raspodjele* ili kumulativna funkcija raspodjele*, odnosno integralna raspodjela* ili kumulativna raspodjela*, tj. može davati udio populacije za koji je slučajna varijabla manja od zadane vrijednosti ili njoj jednaka. Alternativno, može biti i diferencijalna funkcija raspodjele* ili funkcija gustoće vjerojatnosti* ili diferencijalna raspodjela*, tj. davati (moguće infinitezimalan) udio populacije za koji je slučajna varijabla (ili više njih) unutar (moguće infinitezimalnog) intervala vrijednosti.

Napomena 3: Normalizacija zahtijeva da: (i) za diskretnu diferencijalnu funkciju raspodjele zbroj vrijednosti funkcije po svim mogućim vrijednostima slučajne varijable (ili vrijednostima slučajnih varijabli) bude jednak jedinici; (ii) za kontinuiranu diferencijalnu funkciju raspodjele integral preko cijelog područja vrijednosti slučajne varijable (ili područja vrijednosti slučajnih varijabli) bude jednak jedinici; (iii) za integralnu (kumulativnu) funkciju raspodjele, vrijednost funkcije u gornjoj graničnoj vrijednosti slučajne varijable (ili gornjim graničnim vrijednostima slučajnih varijabli) bude jednaka jedinici.

\subsection{7. brojčana funkcija raspodjele, $f_{n}$} (number-distribution function)

diferencijalna brojčana funkcija raspodjele
(differential number-distribution function)
brojčana raspodjela (number distribution)
diferencijalna brojčana raspodjela
(differential number distribution)

Diferencijalna funkcija raspodjele u kojoj je udio tvari specifične vrijednosti ili specifičnog područja vrijednosti slučajne varijable (ili slučajnih varijabli) izražen množinskim udjelom.

\subsection{8. kumulativna brojčana funkcija raspodjele, $F_{\mathrm{n}}$} (cumulative number-distribution function)

integralna brojčana funkcija raspodjele (integral number-distribution function)

\section{kumulativna brojčana raspodjela} (cumulative number distribution)

integralna brojčana raspodjela (integral number distribution)

Kumulativna funkcija raspodjele u kojoj je udio tvari za koji je vrijednost slučajne varijable ili slučajnih varijabli manja od zadane vrijednosti ili njoj jednaka izražen molarnim udjelom. 
2.19. masena funkcija raspodjele, $f_{\mathrm{m},} f_{\mathrm{w}}$ (mass-distribution function)

diferencijalna masena funkcija raspodjele (differential mass-distribution function)

masena raspodjela (mass distribution) diferencijalna masena raspodjela (differential mass distribution)

Diferencijalna funkcija raspodjele u kojoj je udio tvari specifične vrijednosti ili specifičnog područja vrijednosti slučajne varijable (ili slučajnih varijabli) izražen masenim udjelom.

2.20. kumulativna masena funkcija raspodjele, $F_{\mathrm{m}}, F_{\mathrm{w}}$ (cumulative mass-distribution function)

integralna masena funkcija raspodjele

(integral mass-distribution function)

kumulativna masena raspodjela

(cumulative mass distribution)

integralna masena raspodjela

(integral mass distribution)

Kumulativna funkcija raspodjele u kojoj je udio tvari za koji je vrijednost slučajne varijable ili slučajnih varijabli manja od zadane vrijednosti ili njoj jednaka izražen masenim udjelom.

Napomena: Eksperimentom se uobičajeno određuju upravo diferencijalne i kumulativne masene funkcije raspodjele.

\subsection{Schulz-Zimmova raspodjela}

(Schulz-Zimm distribution)

Kontinuirana raspodjela s diferencijalnom brojčanom funkcijom raspodjele oblika:

$$
f_{\mathrm{n}}(X) \mathrm{d} X=\frac{a^{b}}{\Gamma(b)} X^{b-1} \exp (-\mathrm{a} X) \mathrm{d} X,
$$

gdje je $X$ stupanj polimerizacije, a i $b$ su pozitivni ugodivi parametri, a $\Gamma(b)$ je gama-funkcija argumenta $b$.

Napomena 1: Ova je raspodjela ekvivalentna Pearsonovoj raspodjeli tipa III, prema lit.?.

Napomena 2: Za uzorak polimera u kojem su vrijednosti stupnja polimerizacije i relativne molarne mase izravno razmjerne jedna drugoj, Schulz-Zimmova diferencijalna masena funkcija raspodjele je:

$$
f_{\mathrm{m}}(X) \mathrm{d} X=\frac{a^{b+1}}{\Gamma(b+1)} X^{b} \exp (-a X) d X .
$$

\subsection{2. najvjerojatnija raspodjela}

(most probable distribution)

Floryjeva raspodjela (Flory distribution)

Schulz-Floryjeva raspodjela

(Schulz-Flory distribution)

Diskretna raspodjela s diferencijalnom brojčanom funkcijom raspodjele oblika:

$$
f_{\mathrm{n}}(X)=\mathrm{a}(1-\mathrm{a})^{X-1},
$$

gdje je $X$ stupanj polimerizacije uz $0<a \leq 1$.

Napomena 1: Za velike vrijednosti $X$, najvjerojatnija raspodjela konvergira u poseban slučaj Schulz-Zimmove raspodjele $\mathrm{s} b=1$.

Napomena 2: Za uzorak polimera u kojem su vrijednosti stupnja polimerizacije i relativne molarne mase izravno razmjerne jedna drugoj, najvjerojatnija diferencijalna masena funkcija raspodjele je:

$$
f_{m}(X)=a^{2} X(1-a)^{X-1}
$$

\subsection{Poissonova raspodjela (Poisson distribution)}

Diskretna raspodjela s diferencijalnom brojčanom funkcijom raspodjele oblika:

$$
f_{n}(X)=\frac{e^{-a} a^{X-1}}{(X-1) !},
$$

gdje je $X$ stupanj polimerizacije uz $a \geq 0$.

Napomena: Za uzorak polimera u kojem su vrijednosti stupnja polimerizacije i relativne molarne mase izravno razmjerne jedna drugoj, Poissonova diferencijalna masena funkcija raspodjele je:

$$
f_{m}(X)=\frac{X e^{-a} a^{X-1}}{(a+1)(X-1) !} .
$$

\subsection{Tungova raspodjela (Tung distribution)}

Kontinuirana raspodjela s diferencijalnom brojčanom funkcijom raspodjele oblika:

$$
f_{n}(X) d X=\frac{a^{[1-(1 / b)]} b X^{b-2} \exp \left(-a X^{b}\right)}{\Gamma[1-(1 / b)]} d X,
$$

gdje je $X$ stupanj polimerizacije uz $a \geq 0$ i $b>1$.

Napomena: Za uzorak polimera u kojem su vrijednosti stupnja polimerizacije i relativne molarne mase izravno razmjerne jedna drugoj, Tungova diferencijalna masena funkcija raspodjele je:

$$
f_{m}(X) d X=\frac{a b X^{b-1} \exp \left(-a X^{b}\right)}{\Gamma[1-(1 / b)]} d X .
$$

\subsection{5. logaritamska normalna raspodjela} (logarithmic normal distribution)

lognormalna raspodjelan ${ }^{n}$ (log-normal distribution)

Kontinuirana raspodjela s diferencijalnom brojčanom funkcijom raspodjele oblika:

$$
f_{n}(X) d X=\frac{b}{a X^{2} \sqrt{\pi}} \exp \left(-\frac{1}{a^{2}}\left[\ln \left(\frac{X}{b}\right)\right]^{2} \frac{a^{2}}{4}\right) d X,
$$

gdje je $X$ stupanj polimerizacije uz $a, b \geq 0$. 
Napomena: Za uzorak polimera u kojem su vrijednosti stupnja polimerizacije i relativne molarne mase izravno razmjerne jedna drugoj, logaritamska normalna diferencijalna masena funkcija raspodjele je:

$$
f_{m}(X) d X=\frac{b}{a X \sqrt{\pi}} \exp \left(-\frac{1}{a^{2}}\left[\ln \left(\frac{X}{b}\right)\right]^{2}\right) d X .
$$

2.26. disperznost molarne mase, $\bigoplus_{M}$ (molar-mass dispersity)

disperznost molekulske težine ${ }^{\mathrm{n}}$ (molecular-weight dispersity)

\section{disperznost relativne molarne mase} (relative-molar-mass dispersity)

\section{disperznost relativne molekulske mase} (relative-molecular-mass dispersity)

Omjer masenog prosjeka (molarne mase, $M_{\mathrm{m}}$ molekulske težine $^{n}$, relativne molarne mase ili relativne molekulske mase, $M_{r, m}$ ) i brojčanog prosjeka (molarne mase, $M_{n}$, molekulske težinen ${ }^{n}$, relativne molarne mase ili relativne molekulske mase, $M_{r, n}$ ), prema lit. ${ }^{8}$ :

$$
\bigoplus_{M}=M_{m} / M_{n}=M_{r, m} / M_{r, n} .
$$

Napomena: Nikako se ne preporučuje upotreba naziva indeks polidisperznosti* odnosno drugih naziva koji uključuju riječ polidisperznost ${ }^{*}$, za $M_{\mathrm{m}} / M_{\mathrm{n}}, M_{\mathrm{r}, \mathrm{m}} / M_{\mathrm{r}, \mathrm{n}}$.

\section{Literatura}

\section{References}

1. R. G. Jones, J. Kahovec, R. Stepto, E. S. Wilks, M. Hess, T. Kitayama, W. V. Metanomski (ur.), Compendium of Polymer Terminology and Nomenclature, IUPAC recommendations 2008 (the "Purple Book"), RSC Publishing, Cambridge, 2009.

2. P. Kratochvíl, U. W. Suter, Definitions of Terms Relating to Individual Macromolecules, Their Assemblies, and Dilute Polymer Solutions (IUPAC Recommendations 1988), Pure Appl. Chem. 61 (1989) 211-241, doi: https://doi.org/10.1351/ pac198961020211, poglavlje 3 u lit. 1. Hrvatski prijevod: N. Šegudović: Definicije pojmova za pojedinačne makromolekule, njihove skupine i razrijeđene otopine polimera (preporuke IUPAC 1988., preporuke HDKI i HKD 1992.), Kem. Ind. 42(2) (1993) B1-B12.

3. IUPAC, Compendium of Chemical Terminology, 2. izd. (the "Gold Book"), sastavili A. D. McNaught, A. Wilkinson, Blackwell Scientific Publications, Oxford, UK (1997); vidi također: M. Nic, J. Jirat, B. Kosata, XML on-line ispravljena verzija: http://goldbook.iupac.org (2006.-), sadržaj objedinio A. D. Jenkins.

4. A. D. Jenkins, P. Kratochvíl, R. F. T. Stepto, U. W. Suter, Glossary of basic terms in polymer science (IUPAC Recommendations 1996), Pure Appl. Chem. 68 (1996) 2287-2311, doi: https://doi.org/10.1351/pac199668122287, poglavlje 1

\subsection{7. disperznost stupnja polimerizacije, $\bigoplus_{x}$ (degree-of-polymerisation dispersity)}

Omjer masenog prosjeka stupnja polimerizacije, $X_{m}$, i brojčanog prosjeka stupnja polimerizacije, $X_{n}$, prema lit. ${ }^{8}$ :

$$
\bigoplus_{\mathrm{X}}=X_{\mathrm{m}} / X_{\mathrm{n}}
$$

Napomena: Nikako se ne preporučuje upotreba naziva indeks polidisperznosti ${ }^{*}$ odnosno drugih termina koji uključuju riječ polidisperznost ${ }^{*}$, za $X_{m} / X_{n}$.

\subsection{8. disperznost, $\bigoplus$ (dispersity)}

Omjer $M_{m}$ i $M_{n}$ ili omjer $X_{m}$ i $X_{n}$ homopolimera ili alternirajućeg (izmjeničnog) kopolimera dovoljno velike molarne mase, tako da se učinci strukturno različitih završnih skupina u makromolekulama uzorka mogu zanemariti, pa je $X_{\mathrm{n}}$ izravno razmjeran $\mathrm{s} M_{\mathrm{n}}, X_{\mathrm{m}}$ izravno razmjeran $\mathrm{s} M_{\mathrm{m}}$ i $\bigoplus_{\mathrm{M}}=\bigoplus_{\mathrm{X}}=\emptyset_{\text {, }}$ prema lit. ${ }^{8}$.

Napomena 1: Disperznost je mjera disperzije (ili rasapa) funkcije raspodjele molarne mase, molekulske težine ${ }^{n}$, relative molarne mase ili stupnja polimerizacije. Za jednoliki polimer $\emptyset=1$; za polimer dovoljno visokog $X_{n}$ s Poissonovom raspodjelom molarnih masa, molekulskih težinan ${ }^{n}$, relativnih molarnih masa ili relativnih molekulskih masa $Ð \approx 1$; a za polimer dovoljno visokog $X_{\mathrm{n}}$ s najvjerojatnijom raspodjelom molarnih masa, molekulskih težinan, relativnih molarnih masa ili relativnih molekulskih masa $€ \approx 2$.

Napomena 2: Za kopolimer koji nije alternirajući (izmjenični) $X_{n}$ se ne može smatrati izravno razmjernim s $M_{n}$ niti $X_{w}$ izravno razmjernim $s M_{w}$. Tada je nužno ustvrditi rabi li se $\bigoplus_{M}$ ili $\bigoplus_{x}$. u lit. 1. Hrvatski prijevod: V. Jarm, Glosar osnovnih pojmova u znanosti o polimerima (preporuke IUPAC 1996., preporuke HDKI i HKD 1998.), Kem. Ind. 47(12) (1998) B5-B19.

5. P. J. Flory, Statistical Mechanics of Chain Molecules, Interscience Publishers, London, 1969.

6. A. D. Jenkins, Stereochemical definitions and notations relating to polymers (IUPAC Recommendations 1980), Pure Appl. Chem. 53 (1981) 733-752, poglavlje 2 u lit. 1. Hrvatski prijevod: V. Jarm, Z. Smolčić Žerdik, Stereokemijske definicije i oznake koje se odnose na polimere (preporuke IUPAC 1980., preporuke HDKI i HKD 1988.), Kem. Ind. 37(10) (1988) B38-B50.

7. M. G. Kendall, Advanced Theory of Statistics, volumen 1, Charles Griffin, London, 1948.

8. R. F. T. Stepto, Dispersity in polymer science (IUPAC Recommendations 2009), Pure Appl. Chem. 81 (2009) 351-353, doi: https://doi.org/10.1351/PAC-REC-08-05-02; Erratum ibid. 81 (2009) 781, doi: https://doi.org/10.1351/PACREC-08-05-02 erratum. Hrvatski prijevod: M. Rogošić, Disperznost u polimernoj znanosti (preporuke IUPAC 2009., preporuke HDKI i HKD 2012.), Kem. Ind. 61 (5-6) (2012) 305-309.

9. W. J. Work, K. Horie, M. Hess, R. F. T. Stepto, Definitions of terms related to polymer blends, composites, and multiphase polymeric materials (IUPAC Recommendations 2004), Pure Appl. Chem. 76 (2004) 1985-2007, doi: https:// 
doi.org/10.1351/pac200476111985, poglavlje 9 u lit. 1. Hrvatski prijevod: G. Bogdanić, A. Erceg Kuzmić, R. Vuković, Definicije osnovnih pojmova koji se odnose na polimerne mješavine, kompozite i višefazne polimerne materijale (preporuke IUPAC 2004., preporuke HDKI i HKD 2009.), Kem. Ind. 58(9) (2009) 387-403.

10. A. E. Alexander, P. Johnson, Colloid Science, poglavlje XIV, Oxford University Press, Oxford, 1950.

11. C. Tanford, Physical Chemistry of Macromolecules, poglavlje 6, John Wiley, New York, 1961
12. B. J. Berne, R. Pecora, Dynamic Light Scattering with Applications to Chemistry, Biology and Physics, John Wiley, New York, 1976.

Ponovno objavljivanje ili reprodukcija ovog izvješća ili njegova pohrana i/ili širenje elektroničkim putem dopuštena je bez formalne IUPAC-ove dozvole uz uvjet jasno vidljivog isticanja izvora, s punom referencijom, oznakom za copyright (C), imenom IUPAC i godinom objavljivanja. Objavljivanje prijevoda na drugi jezik podložno je dodatnom uvjetu prethodnoga odobravanja od nadležne nacionalne organizacije pri IUPAC-u.

\title{
SUMMARY
}

\author{
Definitions of Terms Relating to Individual Macromolecules, \\ Macromolecular Assemblies, Polymer Solutions, \\ and Amorphous Bulk Polymers (Part I) \\ (IUPAC Recommendations 2014) \\ Translated by Marko Rogošić
}

This document defines terms relating to the properties of individual macromolecules, macromolecular assemblies, polymer solutions, and amorphous bulk polymers. In the section on polymer solutions and amorphous bulk polymers, general and thermodynamic terms, dilute solutions, phase behaviour, transport properties, scattering methods, and separation methods are considered. The recommendations are a revision and expansion of the IUPAC terminology published in 1989 dealing with individual macromolecules, macromolecular assemblies, and dilute polymer solutions. New terms covering the principal theoretical and experimental developments that have occurred over the intervening years have been introduced. Polyelectrolytes are not included.

\section{Keywords}

Amorphous polymers, bulk polymers, IUPAC Polymer Division, macromolecular assemblies, macromolecules, polymer phase behaviour, polymer solutions, polymer thermodynamics, scattering properties, separation methods, transport properties

University of Zagreb

Faculty of Chemical Engineering and Technology

Marulićev trg 19

10000 Zagreb, Croatia
Nomenclature note Received November 30, 2015 Accepted May 18, 2016 